\title{
Glomerulocystic Kidney-Report of an Adult Case
}

\author{
Eiichi NaKao, Takao Suga, Masayuki Endoh, Yasuo Nomoto and Hideto SaKaI
}

\begin{abstract}
A 32-year-old adult case of glomerulocystic kidney disease (GCK) is reported. He had brain and muscle atrophy, probably due to congenital malformation. Progressive renal failure developed and he died. Autopsy disclosed multiple tiny cysts exclusively in the renal cortices. Microscopic study revealed that the cysts were dilated Bowman's spaces. This case is the 12th adult case reported in the world.
\end{abstract}

(Internal Medicine 32: 742-744, 1993)

Key words: cystic kidney, Bowman's space, brain atrophy

\section{Introduction}

Glomerulocystic kidney disease (GCK) which involves bilateral cortical polycystic renal changes due to uniform dilatation of Bowman's capsule was named by Taxy and Filmer in 1976 (1). Since then, there have been many case reports in newborns and infants. Eleven adult cases have been reported since the first report of a 25-year-old female by Dosa et al (2). We treated a 32-year-old male with renal dysfunction of unknown etiology associated with muscle and brain atrophy. GCK was disclosed by autopsy in the present case. This rare entity of cystic disease should be considered in the differential diagnosis of renal dysfunction of unknown cause.

\section{Case Report}

A 32-year-old male was referred to Tokai University Hospital in November 1989 because of advanced renal dysfunction (serum creatinine: $4.0 \mathrm{mg} / \mathrm{dl}$ ). He had postbulbar optic neuritis and elevated intracranial pressure at the age of 13 , but no tumor was noted by craniotomy at that time. He had experienced several episodes of disturbance of consciousness from epileptic seizures since the age of 14. Dementia of unknown etiology had also developed since that age. He was admitted to another hospital and was diagnosed as suspected Leigh encephalopathy (mitochondrial cerebromyopathy) and other metabolic disease of the neurons although no definite diagnosis was made. Advanced renal disfunction was disclosed at the age of 32 by a local doctor. None of his family members had renal problems.

Physical examination on admission to our hospital revealed anemic conjunctiva and diffuse muscle atrophy. His blood pressure and body temperature were normal. No skin rash, lymphoadenopathy or joint deformity was observed. There was no peripheral edema. As depicted in Table 1, urinalysis disclosed no albuminuria, glucosuria or microhematuria except for high excretion of $\beta_{2}$ microglobulin $(8.79 \mu \mathrm{g} / \mathrm{ml}$; normal $<0.25 \mu \mathrm{g} / \mathrm{ml})$. Normocytic anemia $\left(205 \times 10^{4} / \mu 1\right.$ red blood cells $)$ and renal dysfunction $(4.7 \mathrm{mg} / \mathrm{dl}$ of serum creatinine) were demonstrated. Ultrasonography and CT scan showed bilateral atrophic kidneys with several small cysts. After admission, his general status gradually declined with occasional convulsions and disturbed consciousness; he died on February 24, 1990.

Autopsy disclosed marked brain, muscle and kidney atrophy. There was incomplete necrosis (diameter: $1.5 \times 2.0 \mathrm{~cm}$ ) in the bilateral putamen. Necrosis was also observed in the gray matter with growth of vessels. Dilations of the third ventricle of the cerebrum and aqueductus cerebri were noted, perhaps due to cerebral atrophy associated with slight necrosis in the peripheral area of the aqueductus cerebri. There was myelinoclasis in the optic nerve, and gliosis in the posterior lobe. Necrotic changes were also noted in the gray matter of the spinal cord, especially in the thoracic cord. These findings might explain the postbulbar optic neuritis, disturbance of consciousness and dementia.

Marked muscle atrophy was noted in the extremities. Muscle fibers were occasionally necrotic and no neurogenic change was observed. There was degeneration of mitochondria in the skeletal muscle. Both kidneys were atrophic (rt. $90 \mathrm{~g}$, 1t. $70 \mathrm{~g}$ ) and tiny multiple cysts (max. dia. $4 \mathrm{~mm}$ ) were located exclusively in the cortices (Fig. 1). A microscopic study showed normal to atrophic glomeruli in the markedly dilatated Bowman's capsules (Fig. 2). About 20\% of Bowman's capsules were normal in size microscopically. Tubuli showed a thyroid pattern but were not dilatated. Intra-glomerular components were normal to slightly sclerotic although some of them showed poor expansion. Interstitial fibrosis and slight mononuclear cell

From the Division of Nephrology and Metabolism, Department of Internal Medicine, School of Medicine, Tokai University, Isehara

Received for publication March 22, 1993; Accepted for publication September 21, 1993

Reprint requests should be addressed to Dr. Eiichi Nakao, Division of Nephrology and Metabolism, Department of Internal Medicine, Tokai University, Isehara, Kanagawa 259-11 
Table 1. Laboratory Data on Admission

\begin{tabular}{|c|c|c|c|}
\hline \multicolumn{2}{|c|}{ Complete blood study } & \multicolumn{2}{|l|}{ Serum study } \\
\hline WBC & $7,000 / \mu \mathrm{l}$ & $\operatorname{IgG}$ & $1,730 \mathrm{mg} / \mathrm{dl}$ \\
\hline $\mathrm{RBC}$ & $205 \times 10^{4} / \mu 1$ & IgA & $291 \mathrm{mg} / \mathrm{dl}$ \\
\hline $\mathrm{Hgb}$ & $6.4 \mathrm{~g} / \mathrm{dl}$ & $\operatorname{IgM}$ & $246 \mathrm{mg} / \mathrm{dl}$ \\
\hline Hct & $16.8 \%$ & $\mathrm{C} 3$ & $71 \mathrm{mg} / \mathrm{dl}$ \\
\hline Plt & $17 \times 10^{4} / \mu \mathrm{l}$ & $\mathrm{C} 4$ & $40 \mathrm{mg} / \mathrm{dl}$ \\
\hline Chemical study & & $\mathrm{CH}_{50}$ & $58.8 \mathrm{U} / \mathrm{ml}$ \\
\hline UN & $102 \mathrm{mg} / \mathrm{dl}$ & VLDL & $(-)$ \\
\hline $\mathrm{Cr}$ & $4.7 \mathrm{mg} / \mathrm{dl}$ & HBsAg & $(-)$ \\
\hline $\mathrm{Na}$ & $139 \mathrm{mEq} / \mathrm{l}$ & ANA & $(-)$ \\
\hline $\mathrm{K}$ & $5.8 \mathrm{mEq} / \mathrm{l}$ & ESR & $35 / 75 \mathrm{~mm}$ \\
\hline $\mathrm{C} 1$ & $112 \mathrm{mEq} / \mathrm{l}$ & \multicolumn{2}{|c|}{ Coagulation study } \\
\hline $\mathrm{TP}$ & $6.9 \mathrm{~g} / \mathrm{dl}$ & PT & $9.8 \mathrm{sec}(10.6 \mathrm{sec})$ \\
\hline Alb & $3.7 \mathrm{~g} / \mathrm{dl}$ & PTT & $34.7 \mathrm{sec}(31.8 \mathrm{sec})$ \\
\hline T-Bil & $0.2 \mathrm{mg} / \mathrm{dl}$ & Fibrinogen & $276 \mathrm{mg} / \mathrm{dl}$ \\
\hline GOT & $42 \mathrm{IU} / 1$ & \multicolumn{2}{|l|}{ Urinary analysis } \\
\hline GPT & $22 \mathrm{IU} / \mathrm{l}$ & Protein & $(-)(0.16 \mathrm{~g} /$ day $)$ \\
\hline LDH & $31 \mathrm{IU} / \mathrm{l}$ & Glucose & $(-)$ \\
\hline T-chol & $105 \mathrm{mg} / \mathrm{dl}$ & OB & $(-)$ \\
\hline TG & $52 \mathrm{mg} / \mathrm{dl}$ & \multicolumn{2}{|l|}{$\beta_{2}$ microglob } \\
\hline$B_{2}$ microglob & $12.7 \mu \mathrm{g} / \mathrm{ml}$ & \multicolumn{2}{|c|}{$8.79 \mu \mathrm{g} / \mathrm{ml}(<0.25 \mu \mathrm{g} / \mathrm{ml})$} \\
\hline
\end{tabular}

ECG: posterior and lateral cardiac ischemia susp, EMG: lower motor neuron lesion susp, EEG: diffuse $\theta$ pattern, Abd US: atrophic kidney (Lt. $83 \times 48 \mathrm{~mm}$ Rt. $62 \times 38 \mathrm{~mm}$ ), Abd CT: atrophic kidney and cystic lesion.

(Footnote Hgb: hemoglobin, Hct: hematocrit, Plt: platelet, Cr: creatinine, TBil: total bilirubin, T-chol: total cholesterol, TG: triglyceride, $\beta_{2}$ microglob: $\beta_{2}$ microglobulin, sec: second, OB: occult blood)

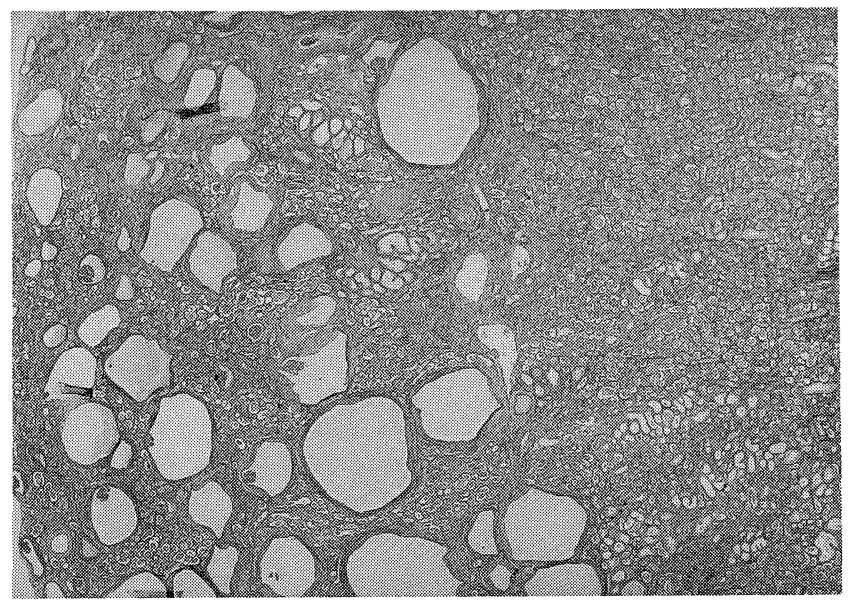

Fig. 1. Tiny multiple cysts are shown exclusively in the cortices (Azan stain, $\times 5$ ).

infiltration were observed in the tubulo-interstitial area (Fig. 3). There was no medullary atrophy and no urinary tract abnormalities.

These findings suggested that this patient had GCK and muscle and brain atrophy, probably due to Leigh encephalopathy or other metabolic abnormalities.

\section{Discussion}

Since the first case of GCK characterized by dilatation of

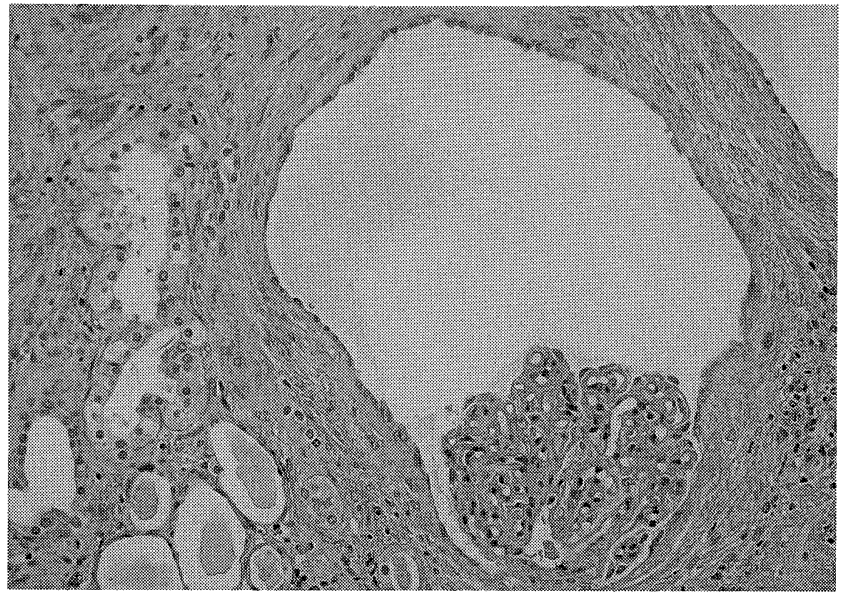

Fig. 2. Atrophic glomeruli are shown in markedly dilated Bowman's capsules (HE stain, $\times 400$ ).

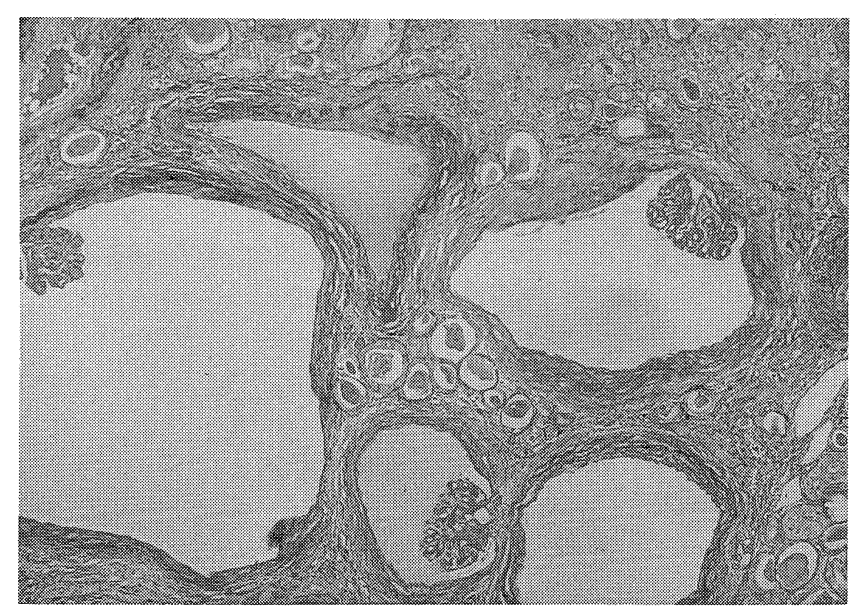

Fig. 3. Interstitial fibrosis and mononuclear cell infiltration are seen in the tubulo-interstitial area (Azan stain, $\times 200$ ).

Bowman's capsule reported by Taxy and Filmer in 1976 (1), many infant and child cases have been reported. Many of the children with this condition died from progressive renal failure or other associated congenital anomalies. Eleven adult cases of GCK have been reported since the first report by Dosa et al in 1984 (Table 2). Most cases were sporadic except for those that reported by Carson et al (5) and Kaplan et al (7). Associated complications were heterogeneous and consisted of both acquired and congenital complications. The presented case had brain atrophy with mild necrosis and muscle atrophy, probably due to mitochondrial cerebromyopathy. However, the precise pathogenetic mechanism of GCK was not clear in this case. Adult cases of GCK have been reported to be associated with various disorders as shown in Table 2. Therefore, GCK might not be a distinct clinicopathological entity, but rather an associated pathological condition. Further accumulation of GCK cases is necessary to elucidate the pathogenesis of this rare renal 
NAKAO et al

Table 2. Adult Cases of Glomerulocystic Kidney

\begin{tabular}{|c|c|c|c|c|c|}
\hline Age (year) & Sex & Complications & Author & Reference No. & Year \\
\hline (1) 25 & $\mathrm{~F}$ & Tbc (lung, abdominal lymph nodes, liver, spleen) & Dosa et al & 2) & 1984 \\
\hline (2) 23 & $\mathrm{M}$ & $\begin{array}{l}\text { Retinitis pigmentosa, Hearing loss, RTA type } 1 \\
\text { Growth retardation }\end{array}$ & Kobayashi et al & 9) & 1985 \\
\hline (3) 29 & $\mathrm{M}$ & Glomerulonephritis & Oh et al & 10) & 1986 \\
\hline (4) 18 & $\mathrm{~F}$ & SLE & Carson et al & 3) & 1987 \\
\hline (5) 60 & M & None & Sessa et al & 6) & 1988 \\
\hline (6) 25 & $\mathrm{~F}$ & Dominant inheritance, Pyloric stenosis, Prognathism & Kaplan et al & 4) & 1989 \\
\hline (7) 63 & $\mathrm{M}$ & $\begin{array}{l}\text { Proliferation and cystic dilation of interlobular } \\
\text { bile duct }\end{array}$ & Monma et al & 7) & 1990 \\
\hline (8) 32 & $\mathrm{M}$ & Hypothyroidism & Katoh et al & 11) & 1991 \\
\hline (9) 23 & $\mathrm{~F}$ & Hemolytic-uremic syndrome & Thompson and Morle & ley 12) & 1991 \\
\hline (10) 59 & M & Hypertension & Egashira et al & 5) & 1991 \\
\hline (11) 69 & M & Nephrotic syndrome & Uemasu et al & 8) & 1991 \\
\hline (12) 32 & M & Brain and muscle atrophy & Present case & & 1993 \\
\hline
\end{tabular}

involvement.

Some reports have suggested the usefulness of ultrasonography for diagnosis of GCK (3-5). However, the diameter of many cysts may be too small to obtain a definite diagnosis of GCK. Recently, Egashira et al reported MRI of GCK (5). They indicated uniform low intensity of the renal cortex on T1-weighted images and cortical high intensity similar to the medulla on T2-weighted images. GCK in the presented case was disclosed by autopsy. Ultrasonography and CT scans would not have revealed this condition. Therefore, it appears that tissue diagnosis by renal biopsy might have been the only procedure to obtain a definite diagnosis.

The prognosis of GCK is variable. Many infant and child cases have a poor prognosis because of progressive renal failure or associated congenital malformations. However, three of the 12 adult cases were over $60(6-8)$. This fact indicates that there may be asymptomatic patients. GCK should be considered in the differential diagnosis of cystic disease in adults.

\section{References}

1) Taxy JB, Filmer RB. Glomerulocystic kidney: Report of a case. Arch Pathol Lab Med 100: 186, 1976.
2) Dosa S, Thompson AM, Abraham A. Glomerulocystic kidney disease: Report of an adult case. Am J Clin Pathol 82: 619, 1984.

3) Carson RW, BediD, Cavallo T, DuBose TD. Familial adult glomerulocystic kidney disease. Am J Kid Dis 9: 154, 1987.

4) Kaplan BS, Gordon I, Pincott J, Barratt M. Familial hypoplastic glomerulocystic kidney disease: A definite entity with dominant inheritance. Am J Med Genet 34: 569, 1989.

5) Egashira K, Nakata H, Hashimoto O, Kaizu K. MR imaging of adult glomerulocystic kidney disease: A case report. Acta Radiologica 32: 251, 1991.

6) Sessa A, Giordano F, Meroni M, Battini G, Torri-Tarelli L, Volpi A. Glomerulocystic kidney in a patient affected with progressive systemic sclerosis. Nephron 48: 173, 1988.

7) Monma N, Tashiro A, Ujiie T. Glomerulocystic kidney; report of two autopsy cases. Jpn J Nephrol 27: 65, 1990.

8) Uemasu J, Maruyama S, Watanabe H, Kawasaki H. Glomerulocystic kidney in a patient with nephrotic syndrome. Nephron 57: 491, 1991.

9) Kobayashi Y, Hiki Y, Shigematsu H, Tateno S, Mori K. Renal retinal dysplasia with diffuse glomerular cysts. Nephron 39: 201, 1985.

10) Oh Y, Onoyama K, Kobayashi K, et al. Glomerulocystic kidneys: Report of an adult case. Nephron 43: 299, 1986.

11) Katoh $K$, Mizuno $K$, Tanaka $K$, et al. A case of glomerulocystic kidney disease associated with hypothyroidism in man. J Med 22: 45, 1991.

12) Thompson SJ, Morley AR. Glomerulocystic kidney disease associated with haemolytic-uraemic syndrome. Nephrol Dial Transplant 6: 131, 1991. 